\title{
CARACTERÍSTICAS QUÍMICAS E FÍSICO-QUÍMICAS DE PEQUIS DA CHAPADA DO ARARIPE, CEARÁ ${ }^{1}$
}

\author{
MARIA ELISABETH BARROS DE OLIVEIRA², NONETE BARBOSA GUERRA ${ }^{3}$, \\ ALINE DE HOLANDA NUNES MAIA ${ }^{4}$, RICARDO ELESBÃO ALVES 5 , \\ NÁDIA MARIA DOS SANTOS MATOS ${ }^{5}$, FRANCISCA GLEICIENE MARTINS SAMPAIO5, \\ MARIA MICHELINE TEIXEIRA LOPES
}

RESUMO - O objetivo deste trabalho foi avaliar a qualidade do pequi. Para isso, frutos maduros colhidos de trinta e cinco pequizeiros (Cariocar coriaceum Wittm.) nativos, provenientes da Chapada do Araripe, Estado do Ceará, foram avaliados quanto as suas características químicas e físico-químicas. Na polpa do fruto, foram determinados $\mathrm{pH}$, acidez total titulável (ATT), sólidos solúveis ( ${ }^{\circ}$ Brix), açúcares solúveis totais (AST), relação ${ }^{\circ}$ Brix/acidez, atividade de água, proteína, carboidratos totais e valor energético total; na polpa e amêndoa, umidade, lipídios, cinzas e minerais (Ca, Mg, P, K, Cu, Fe, Mn, Na e Zn). As plantas apresentaram grande variabilidade para a maioria das características avaliadas. As maiores variabilidades foram observadas para a acidez, açúcares totais e proteína. Em relação aos minerais, a maior variabilidade foi observada para o cobre na polpa e sódio na amêndoa. A menor variabilidade foi detectada para a atividade de água, pH e umidade da polpa, em ordem crescente. Seis plantas destacaram- se por apresentarem percentagem de lipídios (polpa e amêndoa) superiores à média deste estudo. A composição em minerais variou entre as amostras (onze plantas), destacando-se, em termos quantitativos, o potássio na polpa e o fósforo na amêndoa. A amêndoa é mais rica em minerais do que a polpa. A polpa do pequi, face às características de baixa acidez, alto $\mathrm{pH}$ e alta atividade de água, apresenta-se propícia ao desenvolvimento de microrganismos patogênicos e à deterioração. Além disso, a presença de nutrientes, temperatura e a disponibilidade de oxigênio são fatores importantes que devem ser considerados durante o processamento e armazenamento por favorecerem a oxidação dos lipídios. Os resultados demonstram a importância nutricional do pequi, principalmente de sua amêndoa, pelo elevado teor de lipídios e minerais.

Termos para indexação: Caryocar coriaceum, frutas nativas, caracterização química.

\section{CHEMICAL AND PHYSICAL-CHEMICAL CHARACTERISTICS IN PEQUI FROM THE CHAPADA DO ARARIPE, CEARÁ, BRAZIL}

\begin{abstract}
The aim of this work was to evaluate the quality of "pequi” (Caryocar coriaceum Wittm.). Mature fruits from thirty five native pequi plants (Cariocar coriaceum Wittm.), grown in the Chapada do Araripe, State of Ceará were harvested and analyzed as to chemical and physical-chemical characteristics. Pulp content were evaluated for $\mathrm{pH}$, acidity, soluble solids, total sugar, ratio ${ }^{\circ}$ Brix/acidity, water activity, protein, total carbohydrate and total energy, the pulp and kernel moisture, fat, ash and minerals (Ca, Mg, $\mathrm{P}, \mathrm{K}, \mathrm{Cu}, \mathrm{Fe}, \mathrm{Mn}, \mathrm{Na}$ and $\mathrm{Zn}$ ). A high variability for these characteristics was observed among plants. The highest variability in the pulp samples was observed for total acidity (TTA), total sugars and protein, and the lowest for water activity, $\mathrm{pH}$ and moisture, in ascending order. For relation minerals, greater variability was observed for copper in the pulp and sodium in the kernel. Six plants stood out by presenting percentage of lipids (pulp and kernel), above the average in this study. Mineral composition varied among samples (eleven plants), high lighting $\mathrm{K}$ in the pulp and $\mathrm{P}$ in the kernel, in quantitative term. The kernel is richer in minerals than the pulp. The pequi pulp, due of low acidity, high $\mathrm{pH}$ and high water activity, is very attractive to the growth of pathogenic microorganisms and predisposed to decay. Moreover, the presence of nutrients, temperature and oxygen availability are important factors to be considered during processing and storage by favoring the lipids oxidation. The results demonstrate the nutritional importance of pequi, especially their kernel due its high lipids and minerals concentrations.
\end{abstract}

Index terms: Caryocar coriaceum, native fruits, chemical characterization.

\footnotetext{
'(Trabalho 055-09). Recebido em: 26-02-2009. Aceito para publicação em: 25-01-2010. Parte da tese de doutorado do primeiro autor ${ }^{2}$ Pesquisadores da Embrapa Agroindústria Tropical. Fortaleza-CE. E- mail: elisabeth@cnpat.embrapa.br, elesbao@pesquisador.cnpq.br ${ }^{3}$ Prof $^{a}$. do Dept ${ }^{0}$. de Nutrição do Centro de Ciências da Saúde da Universidade Federal de Pernambuco, Recife- PE. E-mail: nonete@globo.com ${ }^{4}$ Pesquisadora da Embrapa Meio Ambiente, Rod. SP-340, km 127,5. CEP: 13820-000, Jaguariúna-SP. E-mail:ahmaia@cnpma.embrapa.br ${ }^{5}$ Alunas do Curso de graduação de Engenharia de Alimentos da UFC, Câmpus do Pici s/n. CEP: 60021-970,Fortaleza-CE. E-mail: nadyka_mattos@hotmail.com, gleiciene_sampaio@yahoo.com.br,michelinetl@yahoo.com.br
} 


\section{INTRODUÇÃO}

A Chapada do Araripe, região de grande ocorrência de pequizeiros nativos, está localizada nas confluências dos Estados de Pernambuco, Ceará e Piauí, abrangendo uma área de 1.050.000 hectares, distribuídos em 35 municípios, onde vivem cerca de 700.000 habitantes (Acep, 1999). No topo da Chapada, a sua área é de 7.500 quilômetros quadrados e sua altitude varia de 700 a 1.000 metros. A vegetação é bastante diversificada, variando de acordo com as condições climáticas da região, predominando um Cerradão (formação florestal do bioma Cerrado que apresenta um tipo denso de vegetação) (Carvalho, 2006).

O crescente interesse mundial por frutas nativas do Brasil tem impulsionado a realização de pesquisas no Cerrado, um dos biomas brasileiros que mais contribui para o fornecimento dessas frutas (Santos et al., 2006). Essa tendência vem sendo intensificada à medida que as pesquisas têm comprovado os efeitos benéficos à saúde, exercidos por diversos fitoquímicos, naturalmente presentes nos vegetais (Torres \& Bobet, 2001).

Nesse cenário, encontra-se o pequizeiro, de reconhecido valor socioeconômico e grande aceitabilidade pela população, na sua área de ocorrência. A utilização de seu potencial como matéria-prima para a agroindústria é, entretanto, incipiente devido à necessidade de informações sobre as características químicas e físico-químicas do pequi, principalmente da espécie $C$. coriaceum, como também devido à carência de incentivo governamental para o desenvolvimento da cultura.

O conhecimento das características químicas dos alimentos regionais, tradicionalmente consumidos pela população, é de suma importância, pois gera informações indispensáveis à orientação nutricional, permitindo a composição de uma dieta saudável e, consequentemente, a avaliação do estado nutricional de um indivíduo com base na ingestão alimentar (Taco, 2004). Tem, ainda, a finalidade de controle de qualidade do alimento; desenvolvimento de novos produtos e a monitoração da legislação. Fornecem, também, subsídios à identificação das espécies promissoras, tendo em vista o seu aproveitamento industrial e a aplicação de estudos de melhoramento genéticos.

Do ponto de vista nutricional, sabe-se que a polpa e a amêndoa do pequi apresentam elevado teor de lipídios, comparável ao do abacate, açaí e buriti (Almeida \& Silva, 1994), nos quais prevalecem os ácidos graxos oleico e palmítico (Lima, 1980; Hiane et al., 1992a; Lima et al., 2007). Esta característica confere maior valor energético ao pequi, largamente utilizado na complementação da dieta da população de baixa renda, durante a safra. Embora explorado de forma extrativista como matéria-prima para extração de óleo para diversos fins, pouco se sabe sobre as características de interesse industrial como: $\mathrm{pH}$, atividade de água, sólidos solúveis totais e acidez, preditivas de possíveis alterações do fruto in natura, bem como durante o seu processamento e armazenamento.

Considerando a exiguidade das informações a respeito do pequizeiro, semelhantemente ao que acontece com outras plantas nativas, e o conhecimento de que os dados sobre a composição nutricional e demais características físico-químicas apresentam grande variabilidade entre as plantas, foi realizada esta pesquisa, com frutos da espécie Caryocar coriaceum Wittm., nativa da Chapada do Araripe-CE, visando a obter dados de interesse nutricional, industrial e agronômico que permitam melhor aproveitamento do seu potencial como matéria-prima.

\section{MATERIAL E MÉTODOS}

\section{Material}

Após autorização prévia do IBAMA(Licença $n^{\circ}$ 029/2006NP/COGEF), foram selecionadas 35 plantas (georreferenciadas com GPS), em quatro municípios produtores de pequi,(Barbalha,Crato, Jardim e Missão Velha) da Chapada do Araripe -CE. A colheita dos frutos foi efetuada no início da manhã, no período de janeiro a março de 2007, época do pico da safra. O número de frutos por planta, colhidos no solo, oscilou entre 60 e 80, variando com a produtividade da planta. A busca do registro da planta no Herbário Prisco Bezerra (nº 43163), da Universidade Federal do Ceará, foi realizada para se ter certeza da espécie presente na Chapada.

Os frutos, após a colheita, foram devidamente transportados para o Laboratório de Análise de Alimentos da Embrapa Agroindústria Tropical, onde, após seleção, foram separados em três lotes de, no mínimo, 20 frutos por planta. Estes frutos, após limpeza de sujidades do campo, foram descascados e despolpados manualmente. O caroço obtido foi cortado e retirada a amêndoa, também manualmente. A seguir, polpa e amêndoa foram trituradas, separadamente, em processador doméstico, de modo a obter 35 amostras de polpa e 35 de amêndoa, todas em triplicatas. As amostras foram acondicionadas em potes plásticos e mantidas sob congelamento $\left(-18^{\circ} \mathrm{C}\right)$ para análises posteriores. 


\section{Métodos}

As características químicas e físico-químicas foram determinadas conforme se segue: $\mathrm{pH}$ por potenciômetro digital; sólidos solúveis totais ( ${ }^{\circ} \mathrm{Brix}$ ), na polpa diluída 1:10 (p/p) em refratômetro digital (AOAC, 1992); acidez total titulável (ATT), em 3 g da polpa fresca diluída com $50 \mathrm{~mL}$ de água destilada por titulação com NaOH 0,1 N (IAL, 2005). Os resultados foram expressos em percentagem de ácido cítrico; açúcares solúveis totais (AST) foram extraídos com álcool etílico a $80 \%$ e determinados pelo método da antrona em espectrofotômetro (Spectronic Genesys 2), no comprimento de onda de $620 \mathrm{~nm}$, segundo metodologia descrita por Yemn \& Willis (1954). Os resultados foram expressos em g de glicose por 100 g de polpa; proteínas pelo micro Kjeldahl (Silva, 1999); atividade de água (Aw), instrumental (Aqualab CX-2 Decagon); lipídios, extraídos com hexano em refluxo por $6 \mathrm{~h}$ em aparelho de Soxhlet (IAL, 2005). Os resultados foram expressos em percentual de lipídios por 100 g de amostra; cinzas por incineração em mufla a $550^{\circ} \mathrm{C}$ (IAL, 2005); umidade, em estufa a vácuo a $70^{\circ} \mathrm{C}$ (IAL, 2005); carboidratos totais por diferença (IBGE, 1999) e valor energético total (VET) estimado conforme os fatores de conversão de Atawer de 4Kcal/g de proteína, 4Kcal/g de carboidrato, 4Kcal/g de lipídio (Lehninger, 1986).

A mineralização das amostras foi realizada utilizando solução nítrico/perclórica (3:1 v/v), conforme descrito por Silva (1999). Acerca de 0,5 g de amostra seca, adicionaram-se $8,0 \mathrm{~mL}$ da solução digestora. A mistura permaneceu sob aquecimento durante 4 horas, a $200^{\circ} \mathrm{C}$, em bloco digestor marca TECNAL, modelo TE 007D, até tornar- se uma solução clara, indicando completa digestão da amostra, quando, então, se deixou reduzir o volume para aproximadamente $1,5 \mathrm{~mL}$. Transferiu-se esse volume para balão volumétrico de $50 \mathrm{~mL}$ e aferiu-se o volume com água deionizada. Em seguida, filtrou-se para frascos plásticos e deixou-se armazenados à temperatura ambiente $\left(25^{\circ} \mathrm{C}\right)$ para análises posteriores. O teor de cálcio, magnésio, zinco, manganês, cobre e ferro foi determinado em espectrofotômetro de absorção atômica Perking Elmer, modelo A-Analyst 300, em chama ar/acetileno nas proporções recomendadas pelo fabricante do instrumento para análise desses elementos (Perkin-Elmer, 1996). Para a análise de Ca e Mg, foi utilizado solução de cloreto de lantânio $(0,1 \mathrm{~g} / 100 \mathrm{~mL})$ como supressor de interferência. Os minerais sódio e potássio foram analisados em fotômetro de chama marca Digimed DM - 61, e o fósforo, em espectrofotômetro-plus marca FEMTO, no comprimento de onda de $660 \mathrm{~nm}$ (Silva, 1999). $\mathrm{O}$ teor de minerais foi expresso em $\mathrm{mg}$ do mineral por $100 \mathrm{~g}$ de amostra. A determinação dos minerais foi realizada somente em onze plantas, em função do grande volume de análises. As plantas foram escolhidas por região de colheita.

\section{Estatística}

Os resultados foram avaliados por meio de estatísticas descritivas, utilizando o procedimento MEANS do software estatístico SAS/STAT ${ }^{\circledR}$ (SAS Institute, 2004). Foi também realizada a correlação de Pearson entre as variáveis químicas e físicoquímicas da polpa e da amêndoa. Os testes de média não foram realizados porque os resultados foram obtidos de plantas nativas, não se constituindo em um experimento planejado.

\section{RESULTADOS E DISCUSSÃO}

Os resultados obtidos apresentam uma considerável variabilidade, em termos percentuais, tendência comumente observada em frutos de plantas oriundas de propagação por sementes. Das características físico-químicas avaliadas, a maior variabilidade foi observada para acidez total titulável (Figura 1), seguida em ordem decrescente, dos açúcares solúveis totais (Figura 2) e proteína (Figura 3), enquanto a atividade de água (Figura 4) se destacou pela menor variabilidade. Em relação aos minerais, a maior variabilidade foi exibida pelo cobre na polpa (Tabela 1) e o sódio na amêndoa (Tabela 2), enquanto a menor foi observada para os teores de potássio e fósforo na polpa e Magnésio e potássio na amêndoa.

Em relação ao valor nutricional, a polpa do pequi, que corresponde acerca de $10,5 \%$ do peso do fruto $(90,5 \mathrm{~g})$ (Oliveira 2009), diferentemente da maioria das frutas tropicais, apresenta elevado teor de lipídios (Figura 5) que contribui com mais de 70\% do VET (Figura 6). O valor médio desse constituinte, em base úmida (Figura 5), foi superior aos determinados em frutos da espécie $C$. brasiliense Camb. por Vera et al. (2007) e Ferreira et al. (1988) 19 a $20 \mathrm{~g} \%$; 15\%, respectivamente, entretanto inferior aos 32\% e 33\% reportados por Marx et al. (1997) e Lima et al. (2007), no que concerne a C. villosum e C. brasiliense, respectivamente. Em relação aos resultados obtidos pelos últimos autores, convém ressaltar que a diferença deve ser resultante do menor teor de umidade dos pequis por eles analisados. $\mathrm{O}$ teor lipídico, proteico e de carboidratos da polpa do pequi (Figura 7) fornece cerca de $15 \%$ das necessidades calóricas de uma dieta de 2.000 Kcal de um indivíduo adulto.

Em relação à amêndoa, destaca-se o elevado 
teor de lipídios (Figura 8), sendo cerca de 1,5 vez superior ao da polpa (Figura 5), com consequente elevação do VET.

A polpa e a amêndoa do pequi, com 0,6 e 3,4\% de resíduo mineral fixo (Figuras 9 e 10), respectivamente, também diferem entre si quanto ao teor de minerais, conforme Tabelas 1 e 2 . Os resultados obtidos, embora ratifiquem a literatura com relação ao teor de $\mathrm{K}$, tanto na polpa como na amêndoa, destacam nesta, em termos quantitativos, o teor de fósforo. Para Mota (2000), o relevante teor de fósforo da amêndoa pode estar relacionado ao seu elevado teor de proteínas e de lipídios. Este mineral, além de atuar no crescimento tecidual e na manutenção do $\mathrm{pH}$ normal, integra os fosfolipídios da membrana celular. Embora, do ponto de vista nutricional, o teor médio de fósforo da amêndoa dos pequis da Chapada do Araripe (546,2 mg/100g) corresponda a 70\% da Ingestão Diária Recomendada - IDR (Brasil, 1998), é menor que os apresentados na literatura por Ferreira et al. (1988) e Hiane et al. (1992b), 702,0 e 1210,0 mg/100g, respectivamente, para a espécie $C$. brasiliense. Entre os micronutrientes, a predominância do sódio na polpa foi referida por estes últimos autores que, também, referem o zinco como mineral majoritário na amêndoa (5,4 mg/100g), valor superior ao detectado neste trabalho. Este elemento ( $\mathrm{Zn})$, ao qual são atribuídas funções estruturais, enzimáticas, reguladoras e antioxidantes, encontra-se associado a desordens de aprendizado e memória, além de disfunções imunológicas que aumentam a recorrência de quadros infecciosos (Cozzolino, 2008). Assim, observa-se que a amêndoa do pequi apresenta um valor nutricional superior ao da polpa, por conter $\mathrm{Zn}$, $\mathrm{Cu}$ e $\mathrm{Mg}$ em percentuais que correspondem a $21 \%$, $35 \%$ e $122 \%$ da IDR, respectivamente. Os resultados sugerem que o consumo associado de polpa e amêndoa constitui numa alternativa importante para o enriquecimento da dieta regional em relação ao suprimento de minerais.

Os resultados discutidos acima ratificam Lima et al. (2007), quanto à importância nutricional do pequi como fonte de energia e minerais, elevado teor de proteínas da amêndoa, quantitativamente, similar ao apresentado pelas nozes. Estes autores destacaram, ainda, o teor de fibra dietética da polpa, cerca de $87 \%$ do total de carboidratos, e a prevalência dos ácidos oleico e palmítico. O fato de constituir uma boa fonte de ácido graxo monoinsaturado (Lima et al., 2007), o pequi tem potencial para modular, favoravelmente, o perfil lipídico, reduzindo o colesterol total e o LDL.

O pequi também difere da maioria das frutas tropicais no que diz respeito às características de interesse industrial por apresentar um pH (Figura 11) que o classifica como alimento de baixa acidez $(6,9)$ (Figura1), propício ao desenvolvimento de microrganismos patogênicos e à deterioração. Outros fatores como atividade de água (Figura 4), que neste fruto se encontra na faixa III, presença de nutrientes, temperatura e disponibilidade de oxigênio, devem ser considerados durante o processamento e armazenamento, não apenas por exercerem efeito seletivo sobre a microbiota dos alimentos, como também por favorecerem a oxidação dos lipídios, contribuindo para a perda de qualidade do produto. Com relação aos açúcares solúveis totais (Figura 2) e a acidez (Figura 1), encontrou-se um teor superior ao referido por Lima (1980) para a mesma espécie, 3,3\% e 0,2\%, respectivamente, porém uma relação ${ }^{\circ} \mathrm{Brix} / \mathrm{acidez}$ (Figura 12) inferior, o que pode explicar o sabor menos adocicado observado neste trabalho.

Por tratar-se de um fruto oleaginoso, os lipídios tanto da polpa (Figura 5) como da amêndoa (Figura 8) destacam-se como constituintes de maior interesse para exploração industrial. Além de ser empregado na indústria de cosméticos, o óleo do pequi tem considerável importância na farmacopeia popular (Almeida et al., 1994), embora o suporte de informações seja empírico. Neste contexto, sobressaem-se os frutos das plantas 8; 25 e 30 e de 3; 9 e 12, cujas polpas e amêndoas, respectivamente, apresentaram os maiores percentuais desse constituinte.

Observou-se forte correlação (Tabela 3) negativa entre o teor de umidade, lipídios e valor energético total (VET) da polpa. O VET (polpa) apresentou forte correlação positiva com o teor de lipídios, conforme esperado. Em relação à amêndoa, observou-se moderada correlação negativa entre a umidade e o teor lipídios, o que se fundamenta em função da menor umidade da amêndoa (35,2\%) (Figura 14) em relação à polpa (55,6\%) (Figura 13). 
TABELA 1 - Composição de minerais da polpa integral de pequi (Cariocar coriaceum Wittm.) da Chapada do Araripe, Ceará e comparações com as IDRs.

\begin{tabular}{|c|c|c|c|c|c|c|c|c|c|}
\hline \multicolumn{10}{|c|}{ Polpa ${ }^{1}$} \\
\hline \multicolumn{5}{|c|}{ Macronutrientes (mg/100g) } & \multicolumn{5}{|c|}{ Micronutrientes (mg/100g) } \\
\hline Plantas & $\mathbf{C a}$ & Mg & $\mathbf{P}$ & $\mathbf{K}$ & $\mathbf{C u}$ & Fe & Mn & $\mathrm{Na}$ & Zn \\
\hline 1 & 43,38 & 41,82 & 28,14 & 195,16 & 2,69 & 1,83 & 1,34 & 4,75 & 2,23 \\
\hline 2 & 53,66 & 69,53 & 21,95 & 212,74 & 0,47 & 0,97 & 1,84 & 3,36 & 1,88 \\
\hline 5 & 46,02 & 91,14 & 24,92 & 231,83 & 0,25 & 1,09 & 1,13 & 3,05 & 1,63 \\
\hline 6 & 31,33 & 62,94 & 22,89 & 216,82 & 0,43 & 0,59 & 1,20 & 3,46 & 1,18 \\
\hline 12 & 40,84 & 80,12 & 17,29 & 193,96 & 0,46 & 0,37 & 1,46 & 4,63 & 1,05 \\
\hline 13 & 63,32 & 80,26 & 25,40 & 195,89 & 7,17 & 1,44 & 2,02 & 3,04 & 1,38 \\
\hline 14 & 51,29 & 36,07 & 25,08 & 263,81 & 5,52 & 2,01 & 2,47 & 4,18 & 1,47 \\
\hline 19 & 40,16 & 60,19 & 18,29 & 207,27 & 0,48 & 0,65 & 1,33 & 1,78 & 1,43 \\
\hline 26 & 33,58 & 41,75 & 19,23 & 175,53 & 0,45 & 0,69 & 1,66 & 3,08 & 1,10 \\
\hline 29 & 30,76 & 37,22 & 26,03 & 183,74 & 0,42 & 0,74 & 1,36 & 2,50 & 1,02 \\
\hline 33 & 39,25 & 58,83 & 17,76 & 140,31 & 0,36 & 0,72 & 1,63 & 1,19 & 0,69 \\
\hline Mínimo & 30,76 & 36,07 & 17,29 & 140,31 & 0,25 & 0,37 & 1,13 & 1,19 & 0,70 \\
\hline Máximo & 63,32 & 91,14 & 28,14 & 263,81 & 7,19 & 2,01 & 2,47 & 4,75 & 2,23 \\
\hline Média & 43,05 & 59,99 & 22,45 & 201,55 & 1,70 & 1,01 & 1,59 & 3,18 & 1,37 \\
\hline DP & 10,03 & 19,08 & 3,79 & 31,72 & 2,42 & 0,53 & 0,40 & 1,10 & 0,43 \\
\hline CV (\%) & 23,30 & 31,81 & 16,88 & 15,74 & 142,55 & 52,55 & 25,18 & 34,60 & 31,70 \\
\hline IDR & $800 \mathrm{mg}$ & $300 \mathrm{mg}$ & $800 \mathrm{mg}$ & . & $3 \mathrm{mg}$ & $14 \mathrm{mg}$ & $5 \mathrm{mg}$ & . & $15 \mathrm{mg}$ \\
\hline IDR (\%) & 5,4 & 20,6 & 2,8 & . & 46,4 & 7,3 & 31,9 & . & 9,7 \\
\hline
\end{tabular}

${ }^{1}$ Base úmida; IDR: Ingestão Diária Recomendada; DP: desvio padrão; CV: coeficiente de variação.

TABELA 2 - Composição de minerais da amêndoa integral do pequi (Cariocar coriaceum Wittm.) da Chapada Araripe, Ceará e comparações com as IDRs.

\begin{tabular}{|c|c|c|c|c|c|c|c|c|c|}
\hline \multicolumn{10}{|c|}{ Amêndoa $^{1}$} \\
\hline \multicolumn{4}{|c|}{ Macronutrientes (mg/100g) } & \multicolumn{6}{|c|}{ Micronutrientes (mg/100g) } \\
\hline Plantas & $\mathbf{C a}$ & Mg & $\mathbf{P}$ & $\mathbf{K}$ & $\mathbf{C u}$ & Fe & Mn & $\mathrm{Na}$ & Zn \\
\hline 1 & 99,70 & 352,01 & 563,78 & 489,88 & 0,51 & 0,96 & 3,74 & 0,00 & 3,33 \\
\hline 2 & 84,51 & 339,40 & 526,24 & 499,21 & 0,99 & 1,03 & 3,51 & 0,97 & 3,30 \\
\hline 5 & 79,00 & 421,12 & 643,29 & 492,06 & 0,85 & 1,42 & 3,47 & 1,33 & 3,93 \\
\hline 6 & 51,75 & 371,38 & 617,34 & 505,52 & 0,95 & 1,03 & 2,65 & 1,59 & 2,29 \\
\hline 12 & 118,30 & 336,34 & 391,25 & 375,16 & 1,19 & 1,12 & 4,36 & 0,00 & 2,79 \\
\hline 13 & 100,61 & 383,51 & 589,51 & 460,74 & 1,23 & 1,58 & 4,50 & 6,10 & 3,62 \\
\hline 14 & 88,00 & 301,08 & 410,01 & 374,11 & 0,96 & 0,90 & 3,67 & 1,97 & 2,28 \\
\hline 19 & 90,16 & 417,58 & 634,13 & 494,73 & 1,26 & 2,12 & 3,55 & 2,73 & 4,30 \\
\hline 26 & 103,23 & 351,99 & 548,58 & 442,61 & 1,12 & 1,81 & 4,84 & 1,49 & 2,81 \\
\hline 29 & 98,79 & 325,30 & 495,41 & 386,12 & 1,14 & 1,52 & 3,84 & 2,98 & 2,44 \\
\hline 33 & 91,58 & 423,81 & 589,07 & 452,64 & 1,24 & 2,10 & 4,13 & 3,25 & 3,21 \\
\hline Mínimo & 51,74 & 301,08 & 391,25 & 374,11 & 0,51 & 0,90 & 2,65 & 0,00 & 2,28 \\
\hline Máximo & 118,29 & 423,81 & 643,29 & 505,51 & 1,26 & 2,12 & 4,84 & 6,10 & 4,30 \\
\hline Média & 91,42 & 365,77 & 546,24 & 452,07 & 1,04 & 1,42 & 3,84 & 2,04 & 3,12 \\
\hline DP & 16,91 & 41,50 & 84,72 & 51,41 & 0,22 & 0,45 & 0,60 & 1,72 & 0,67 \\
\hline CV (\%) & 18,49 & 11,35 & 15,51 & 11,37 & 21,28 & 31,65 & 15,56 & 84,67 & 21,37 \\
\hline IDR & $800 \mathrm{mg}$ & $300 \mathrm{mg}$ & $800 \mathrm{mg}$ & . & $3 \mathrm{mg}$ & $14 \mathrm{mg}$ & $5 \mathrm{mg}$ & . & $15 \mathrm{mg}$ \\
\hline IDR (\%) & 11,4 & 121,9 & 68,3 & . & 34,7 & 10,1 & 76,8 & . & 20,8 \\
\hline
\end{tabular}

${ }^{1}$ Base úmida; IDR: Ingestão Diária Recomendada; DP: desvio padrão; CV: coeficiente de variação. 


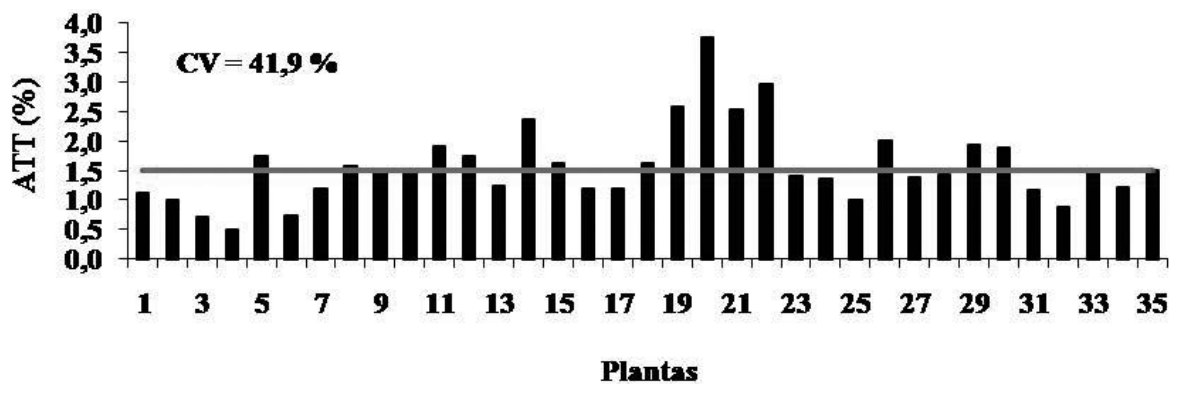

FIGURA 1 - Média e variação da acidez total titulável (ATT) da polpa de frutos de 35 pequizeiros (Cariocar. coriaceum) nativos da Chapada do Araripe, Ceará.

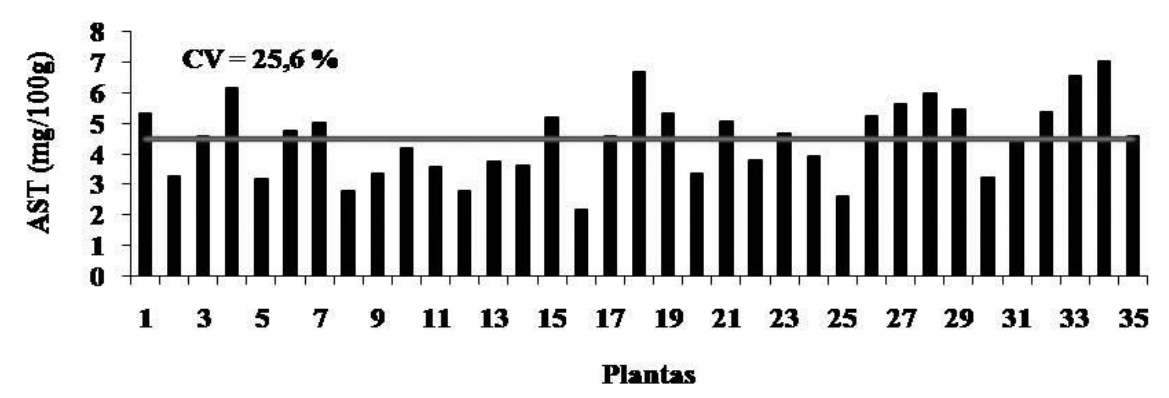

FIGURA 2 - Média e variação dos açúcares solúveis totais (AST) da polpa de frutos de 35 pequizeiros (Cariocar coriaceum) nativos da Chapada do Araripe, Ceará.

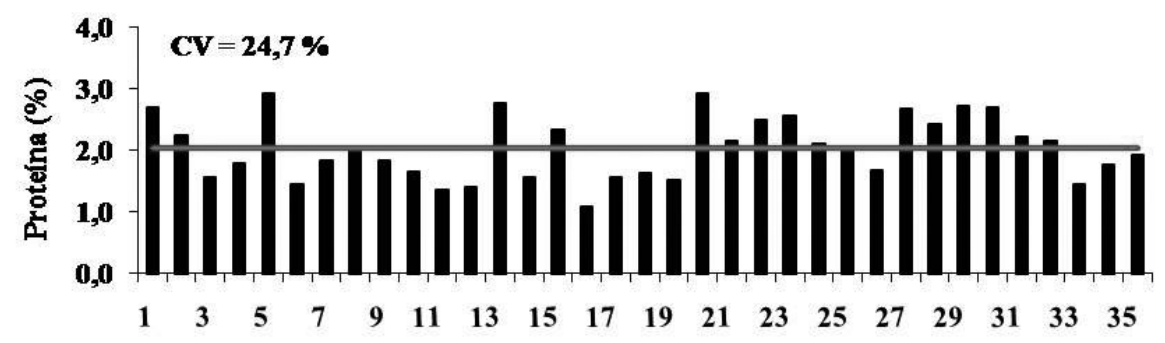

Plantas

FIGURA 3 - Média e variação do teor de proteína da polpa de frutos de 35 pequizeiros (Cariocar coriaceum) nativos da Chapada do Araripe, Ceará.

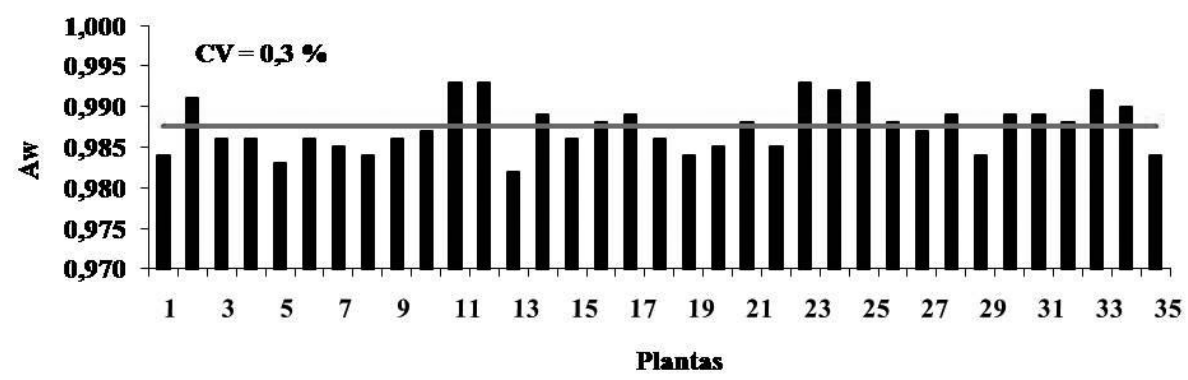

FIGURA 4 - Média e variação da atividade de água (Aw) da polpa de frutos de 35 pequizeiros (Cariocar coriaceum) nativos da Chapada do Araripe, Ceará. 


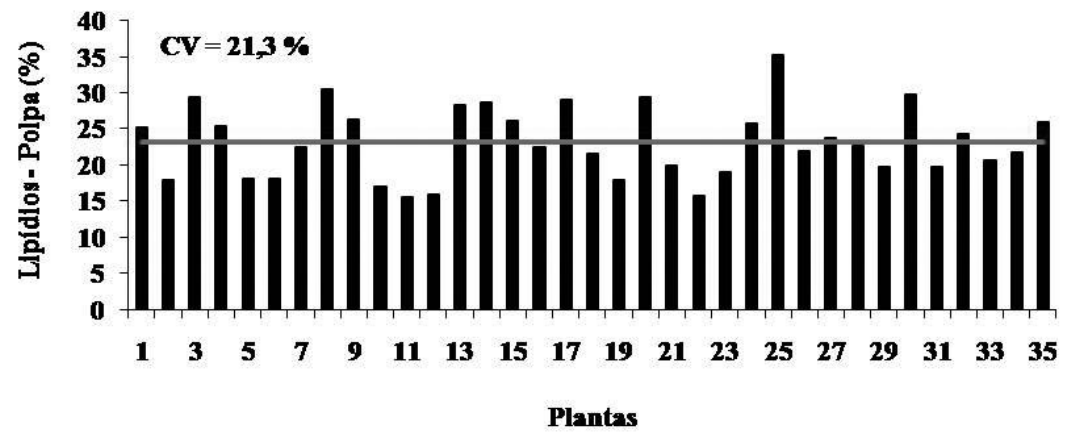

FIGURA5 - Média e variação do teor de lipídios da polpa de frutos de 35 pequizeiros (Cariocar coriaceum) nativos da Chapada do Araripe, Ceará.

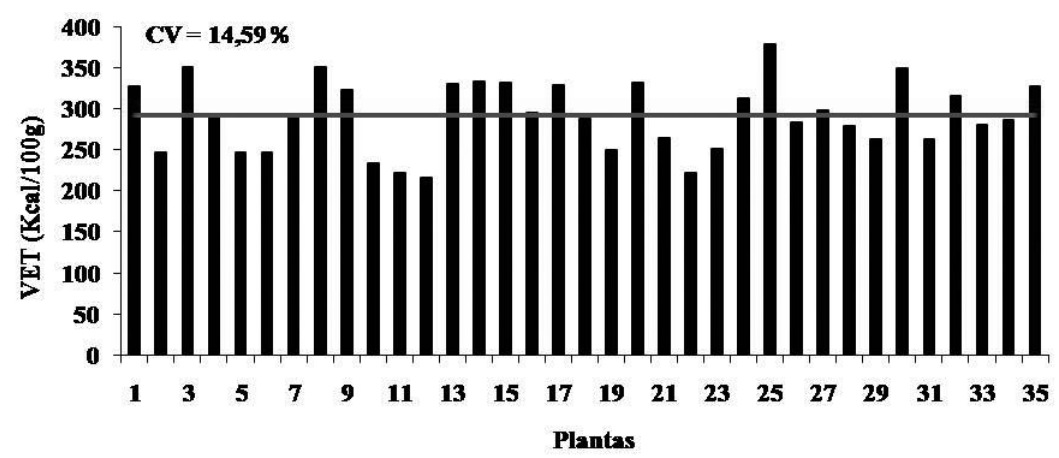

FIGURA 6 - Média e variação do valor energético total (VET) da polpa de frutos de 35 pequizeiros (Cariocar coriaceum) nativos da Chapada do Araripe, Ceará.

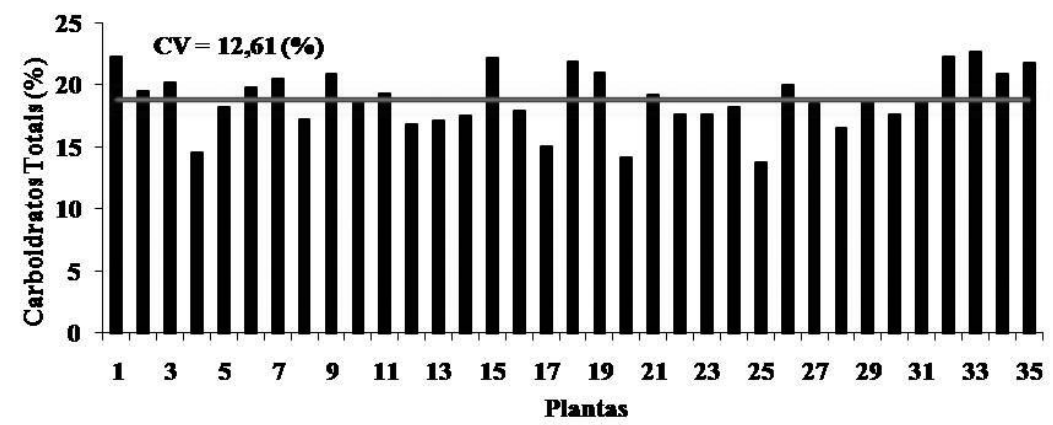

FIGURA 7 - Média e variação do teor de carboidratos da polpa de frutos de 35 pequizeiros (Cariocar coriaceum) nativos da Chapada do Araripe, Ceará.

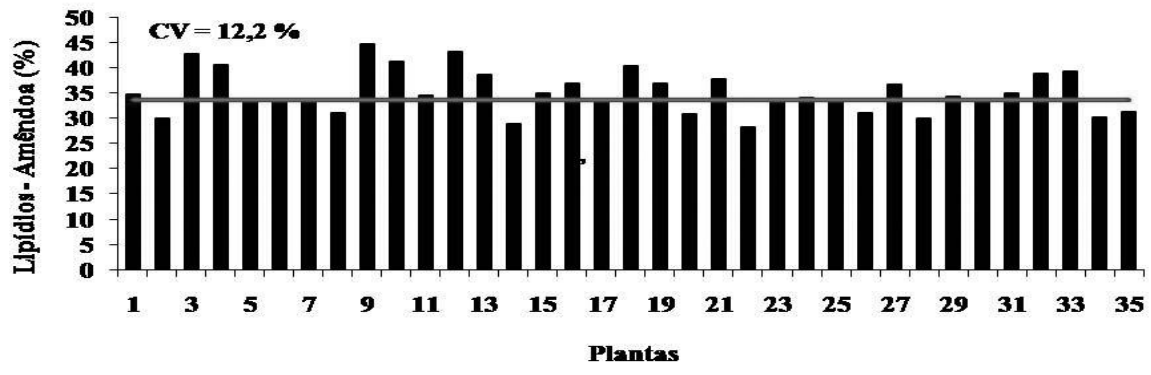

FIGURA 8 - Média e variação do teor de lipídios da amêndoa de frutos de 35 pequizeiros (Cariocar coriaceum) nativos da Chapada do Araripe, Ceará. 


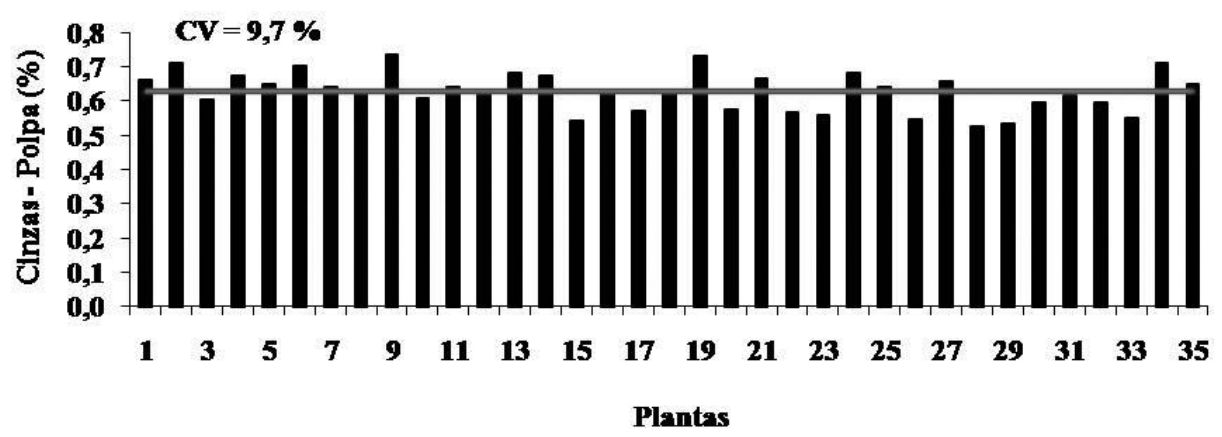

FIGURA 9 - Média e variação do teor de cinzas da polpa de frutos de 35 pequizeiros (Cariocar coriaceum) nativos da Chapada do Araripe, Ceará

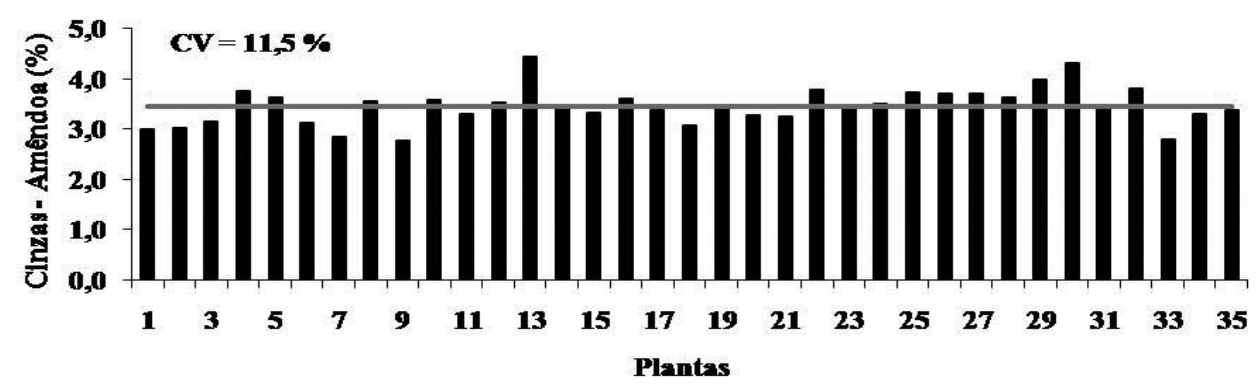

FIGURA 10 - Média e variação do teor de cinzas da amêndoa de frutos de 35 pequizeiros (Cariocar coriaceum) nativos da Chapada do Araripe, Ceará.

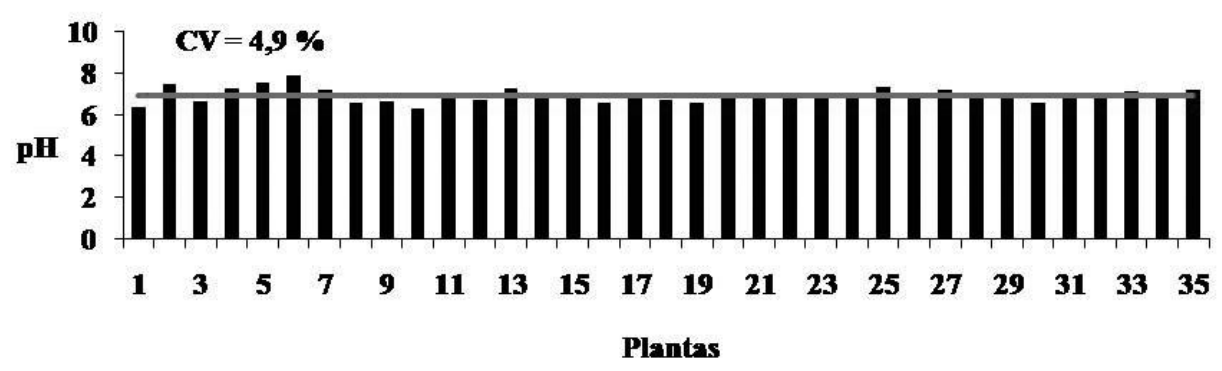

FIGURA 11 - Média e variação do pH da polpa de frutos de 35 pequizeiros (Cariocar coriaceum) nativos da Chapada do Araripe, Ceará.

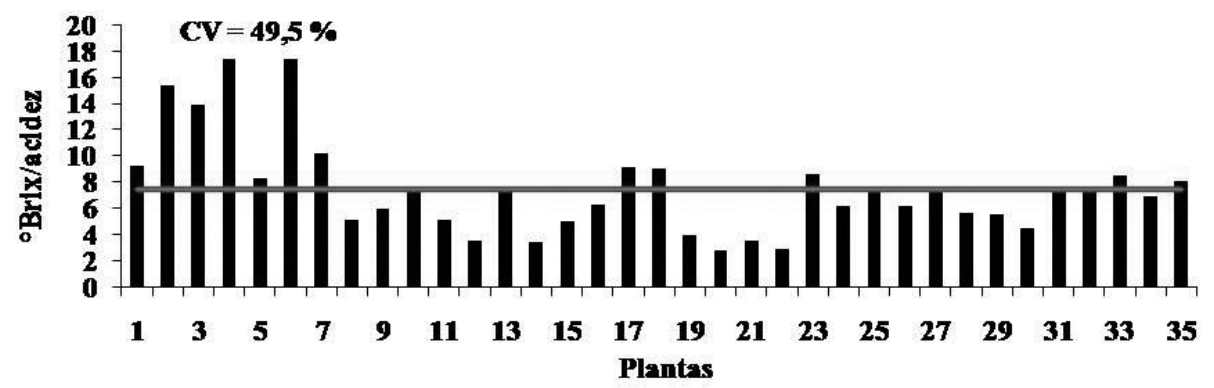

FIGURA 12 - Média e variação da relação ${ }^{\circ}$ Brix/acidez da polpa de frutos de 35 pequizeiros (Cariocar coriaceum) nativos da Chapada do Araripe, Ceará. 


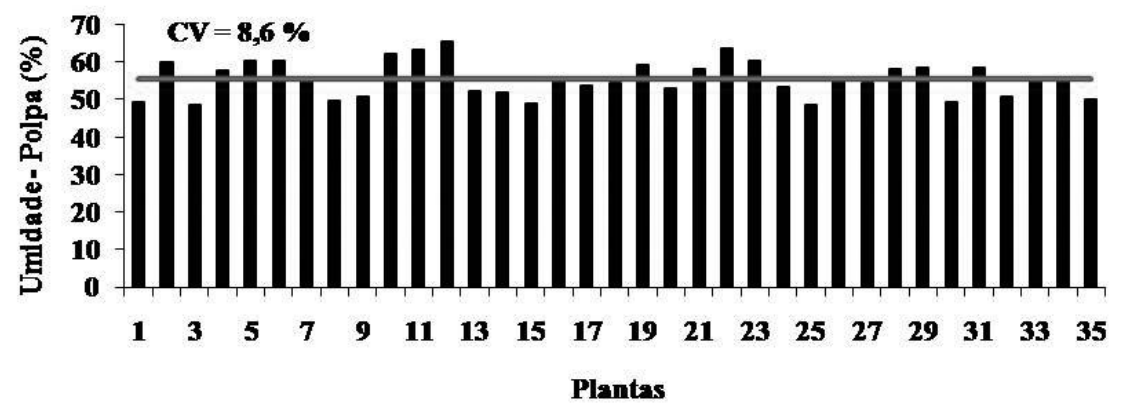

FIGURA 13 - Média e variação do teor de umidade da polpa de frutos de 35 pequizeiros (Cariocar coriaceum) nativos da Chapada do Araripe, Ceará.

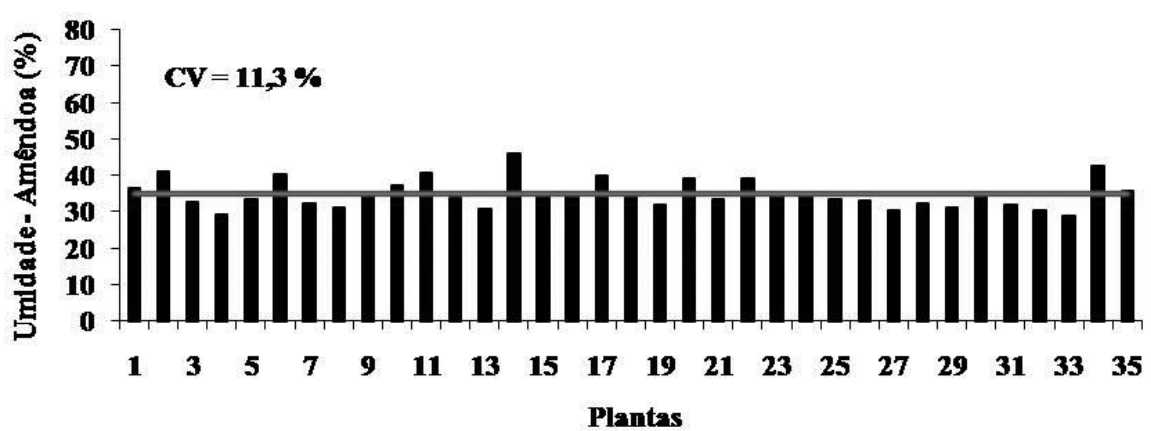

FIGURA 14 - Média e variação do teor de umidade da amêndoa de frutos de 35 pequizeiros (Cariocar coriaceum) nativos da Chapada do Araripe, Ceará

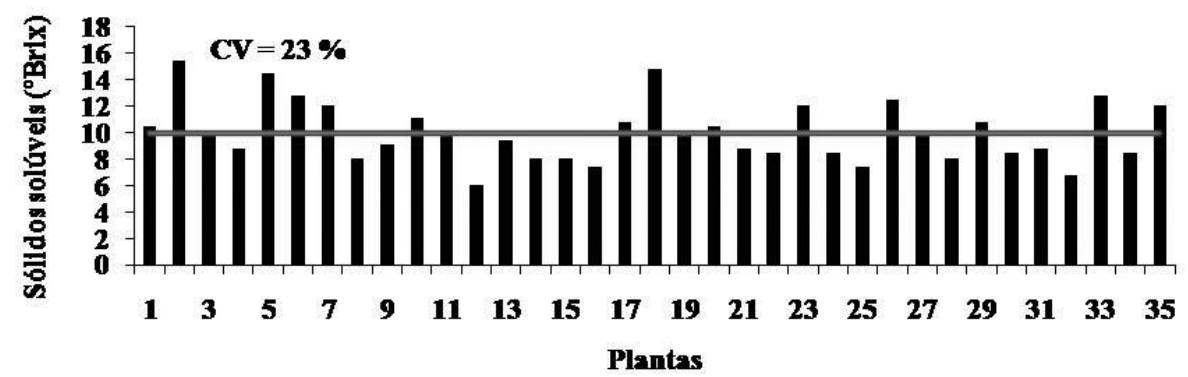

FIGURA 15 - Média e variação do teor de sólidos solúveis ( ${ }^{\circ}$ Brix) da polpa de frutos de 35 pequizeiros (Cariocar coriaceum) nativos da Chapada do Araripe, Ceará. 


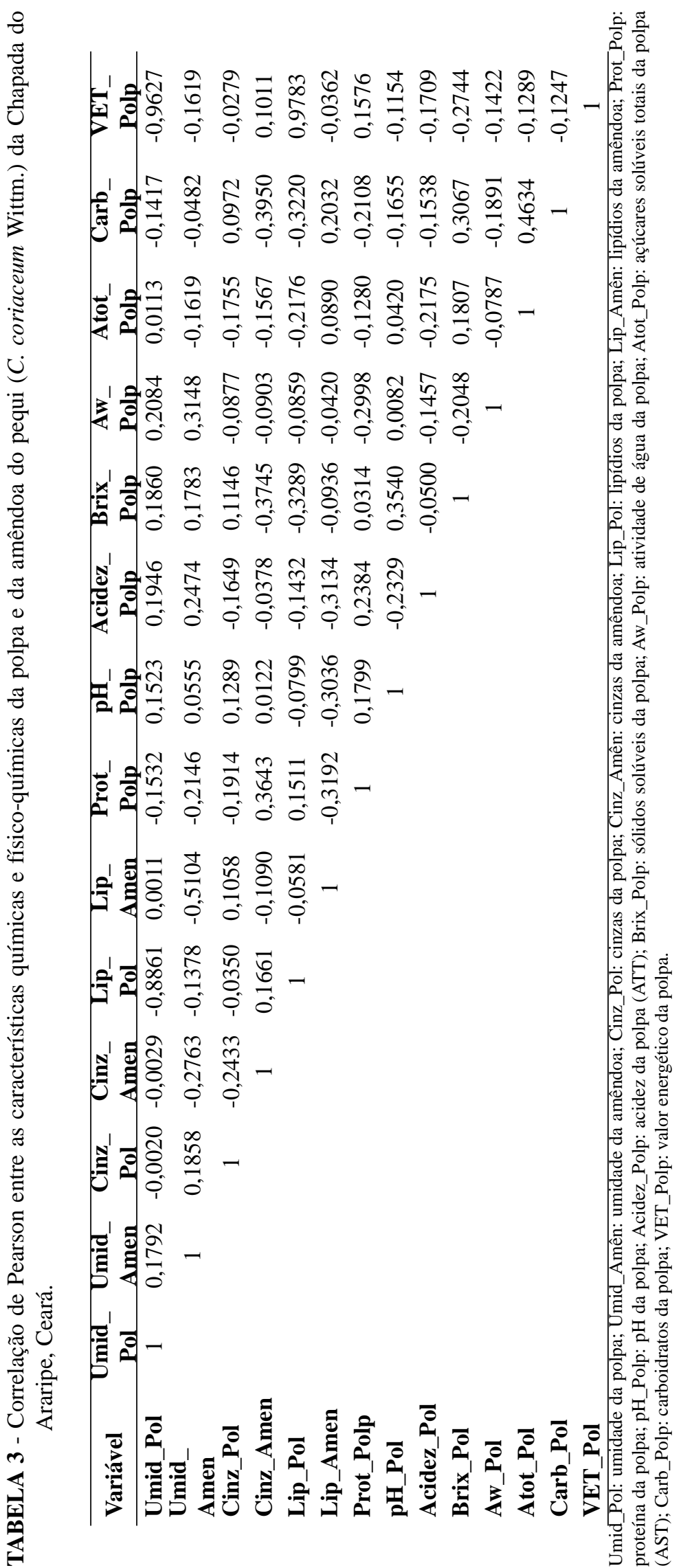




\section{CONCLUSÕES}

1-Os resultados demonstram a importância nutricional do pequi, principalmente de sua amêndoa, pelo elevado percentual de lipídios, proteínas, zinco, cobre e fósforo.

2- A polpa do pequi, face às suas características de baixa acidez, alto $\mathrm{pH}$ e alta atividade de água, apresenta-se propícia ao desenvolvimento de microrganismos patogênicos e à deterioração.

3- Além disso, a presença de nutrientes, temperatura e a disponibilidade de oxigênio são fatores importantes que devem ser considerados durante o processamento e armazenamento por favorecerem a oxidação dos lipídios.

\section{AGRADECIMENTOS}

Ao Banco do Nordeste, pelo suporte financeiro, e ao IBAMA, pelo apoio logístico.

\section{REFERÊNCIAS}

ACEP. Tecnologias agrícolas e de conservação ambiental para o topo da Chapada do Araripe. Fortaleza: FINEP-BNB, 1999.

ALMEIDA, S.P.; SILVA, J.A. Piqui e buriti: importância alimentar para a população dos cerrados. Planaltina: CPAC, 1994. 38p. (Documentos, 54)

AOAC - Association of Official Analytical Chemistry. Official methods of analysis of the Association of Official Analytical Chemistry. $17^{\text {th }}$ ed. Washington, 2002.

BRASIL. Ministério da Saúde. Ingestão diária recomendada (IDR) para adultos. Portaria 33, 13 de janeiro de 1998, da Secretaria de Vigilância Sanitária, 1998.

CARVALHO, A.C.F. Projeto universidades cidadãs. Crato: Universidade Regional do Cariri, 2006. 12 p. Relatório de atividades.

COZZOLINO, S.M.F. O papel do zinco no crescimento e desenvolvimento infantil. In: FISBERG, M.; BARROS, M.J.L. O papel dos nutrientes no crescimento e desenvolvimento infantil. São Paulo: Sarvier, 2008. cap. 4, p-65-82.
FERREIRA, F.R.; BIANCO, S.; DURIGAN, J.F.; BELINGIERI, P.A. Caracterização física e química de frutosmaduros de pequi. In: CONGRESSO BRASILEIRO DE FRUTICULTURA, 9., 1987, Campinas. Anais... Campinas: Sociedade Brasileira de Fruticultura, 1988. v.2, p.643-646.

HIANE, P.A.; RAMOS, M.I.L.; RAMOS FILHO, M.M.; PEREIRA, J.G. Composição centesimal e perfil de ácidos graxos de alguns frutos nativos do estado de Mato Grosso do Sul. Boletim do Ceppa,Curitiba, v.10, n1, p.35-42, 1992a.

HIANE, P.A.; RAMOS, M.I.L.; RAMOS FILHO, M.M.; BARROCAS, G.E.G. Teores de minerais de alguns frutos do Estado de Mato Grosso do Sul. Boletim do Ceppa, Curitiba, v.10, n.2, p.208-214, 1992b.

IAL - Instituto Adolfo Lutz. Métodos físico-químicos para análise de alimentos. 4.ed. Brasília: IAL, 2005. 1018p.

IBGE. Estudo nacional da despesa familiar: tabelas de composição de alimentos. 5.ed. Rio de Janeiro, 1999.

LEHNINGER, A.L. Princípios de bioquímica. São Paulo: Sarvier, 1986. p.211.

LIMA, A.; SILVA, A.M.O.; TRINDADE, R.A.; TORRES, R.P.; MANCINI-FILHO, J. Composição química e compostos bioativos presentes na polpa e na amêndoa do pequi (Caryocar brasiliense Camb.). Revista Brasileira de Fruticultura, Jaboticabal, v.29, n.3, p.695-698,

LIMA, M.T. Caracterização química e física do fruto do pequizeiro (Caryocar coriaceum Wittm.). 1980. 61 f. Dissertação (Mestrado) -Universidade Federal do Ceará, Fortaleza, 1980.

MARX, F.; ANDRADE, E.H.A.; MAIA, J.G. Chemical composition of the fruit pulp of Caryocar villosum. Zeitschift Fuer Lebensmittel Untersuchung/ Food Research and Technology, v.204, p.442-444, 1997.

MOTA, W.F. da; FINGER, F.L.; CASALI, V.W.D. Olericultura: melhoramento genético do quiabeiro.

Viçosa: UFV, 2000. 144p. 
OLIVEIRA, M.E.B. Características físicas, químicas e compostos bioativos em pequis (Caryocar coriaceum Wittm.) nativos da Chapada do Araripe - CE. 2009. 123 f. Tese (Doutorado) - Universidade Federal de Pernambuco, Recife, 2009.

PERKIN-ELMER. Atomic absorption spectroscopy: analytical methods. Norwalk, 1996. 300p.

SANTOS, B.R.; PAIVA, R.; DOMBROSKI, J.L.D.; MARTINOTO, C.; GUEIRA, R.C.; SILVA, A.A.N. Pequizeiro (Caryocar brasiliense Camb.): uma espécie promissora do Cerrado Brasileiro. Lavras: UFLA, 2006. 33p. (Boletim Agropecuário, 66)

SAS INSTITUTE. SAS/GRAPH software: reference, version 8. Cary, 2004. p.801-858.

SILVA, F.C. Manual de análises químicas de solos, plantas e fertilizantes. Brasília, Embrapa Comunicação para Transferência de Tecnologia, Embrapa, Solos, Embrapa Informática para Agricultura, 1999. 370p.
TACO. Tabela brasileira de composição de alimentos. Campinas: NEPA-UNICAMP, 2004. 44p.

TORRES, J.L.; BOBET, R. New flavanol derivatives from grape (Vitis vinifera) byproducts: antioxidant aminoethylthio-flavan-3-ol conjugates from a polymeric waste fraction used as a source of flavonols. Journal of Agricultural and Food Chemistry. Washington, v.49, p.4627-4634, 2001.

VERA, R.; SOUZA, E. R. B. de; FERNANDES, E. P.; NAVES, R. V.; SOARES JÚNIOR, M. S.; CALIARI, M.; XIMENES, P. A. Caracterização física e química de frutos do pequizeiro (Caryocar brasiliense Camb.) oriundos de duas regiões no Estado de Goiás, Brasil. Pesquisa Agropecuária Tropical, Goiânia, v.37, p.93-99, 2007.

YEMN, E. W.; WILLIS, A. J. The estimation of carbohydrate in plant extracts by anthrone. The Biochemical Journal, London, v.57, p.508-514, 1954. 